\title{
Clock Gating Based Energy Efficient and Thermal Aware Design of Latin Unicode Reader for Natural Language Processing on FPGA
}

\author{
Ritu Singh ${ }^{1}$, Kartik Kalia $^{2}$, M H Minver $^{3}$ and D M Akbar Hussain ${ }^{4}$ \\ ${ }^{1,2}$ Gyancity Research Lab, Gurgaon, India \\ ${ }^{3}$ Addalaichenai National College Of Education, Srilanka \\ ${ }^{4}$ Aalborg University, Denmark \\ ${ }^{1}$ rituussingh2@gmail.com, ${ }^{2}$ kartikkalia4@gmail.com, ${ }^{3}$ mhminver@gmail.com, \\ ${ }^{4} a k h @ e t . a a u . d k$
}

\begin{abstract}
In this paper we have aimed to design an energy efficient and thermally aware Latin Unicode Reader. Our design is based on 28nm FPGA (Kintex-7) and 40nm FPGA (Artix7). In order to test the portability of our design, we are operating our design with respective frequency of different mobile architecture. For thermal analysis of our energy efficient design, we have taken temperatures of four different regions from reference. Latin Unicode reader takes 16-bit hexadecimal code of alphabet and clock input. At the end we can conclude that the maximum power consumption is at $2.2 \mathrm{GHz}$ and minimum power consumption is at $1.2 \mathrm{GHz}$. When we talk in terms of temperature we can see that maximum power is consumed at $329.85 \mathrm{~K}$ and minimum power is consumed at $294.15 \mathrm{~K}$. And also the power dissipation is less in the case of 40nm (Artix-6) and is more in the case of 28nm (Kintex-7). Changing the parameter (Temperature) doesn't affect the clock power in both cases (Gated and Non-gated).
\end{abstract}

Keywords: Clock Gating, Latin, Unicode, FPGA, Energy Efficient, VLSI, Thermal Aware

\section{Introduction}

With of international standards (Unicode) it is now possible to develop and deploy online content in local languages across the globe [1]. Unicode is one of the fundamental technological building blocks for exchange of textual information across the globe with the help of computers [14]. Latin Unicode takes input as an alphabet and gives corresponding output like ASCII Digits, ASCII Punctuation, Control Character, C0 Control, Invalid Sign, Lowercase, and Uppercase. Range of Latin Script is 0000 to 007F. Ranges of outputs are shown in Table 1.

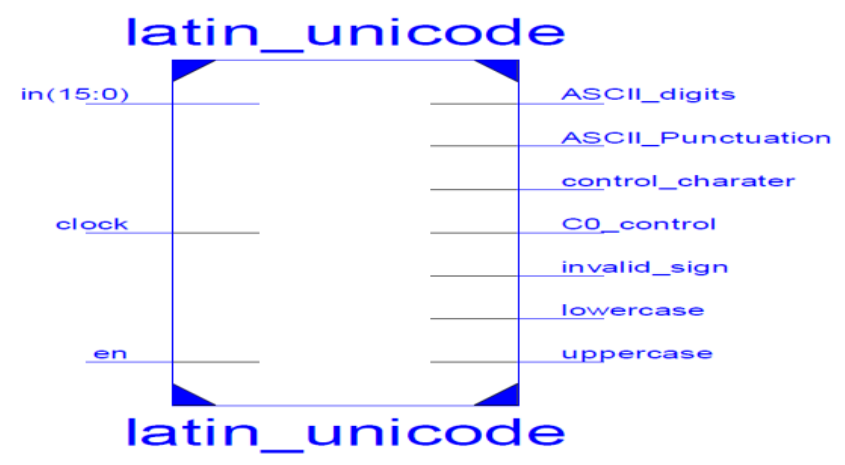

Figure 1. Symbol of Latin Unicode Reader 
Table 1. Range of Latin Unicode Scripts with O/P Port

\begin{tabular}{|c|c|}
\hline Character Type (O/P Port) & Unicode Range \\
\hline ASCII_Digits & $0030-0039$ \\
\hline ASCII_Punctuation & $0020-002 \mathrm{~F}, 003 \mathrm{~A}-0040,005 \mathrm{~B}-$ \\
& $0060,007 \mathrm{~B}-007 \mathrm{E}$ \\
\hline Control_Character & $007 \mathrm{~F}$ \\
\hline C0_control & $0000-001 \mathrm{~F}$ \\
\hline Invalid Sign & - \\
\hline Lowercase & $0041-005 \mathrm{~A}$ \\
\hline Uppercase & $0061-007 \mathrm{~A}$ \\
\hline
\end{tabular}

Table 2. Set of Frequencies Taken In Consideration

\begin{tabular}{|c|c|}
\hline Frequency & Mobile set \\
\hline 1400Mega Hz & Nokia Lumia 710 \\
\hline $1.2 \mathrm{Giga} \mathrm{Hz}$ & Samsung Galaxy Core \\
\hline $2100 \mathrm{Mega} \mathrm{Hz}$ & iPhone6 \\
\hline 1700Mega Hz & HTC/T \\
\hline $1800 \mathrm{Mega} \mathrm{Hz}$ & Micromax X091 \\
\hline $2.2 \mathrm{Giga} \mathrm{Hz}$ & Sony Xperia Z1 \\
\hline
\end{tabular}

Latch free, latch based, and flip-flop based clock gating are clock gating technique as illustrated in Figure 2. Our design is based on 28nm FPGA and 40nm FPGA and the code has been tested on Kintex-7 and Artix-7 FPGA. Clock gating technique is used to achieve energy efficiency in sequential circuit [3], 8-bit ALU [4] and 64-bit ALU [5], global reset ALU [6], and ITC'99-b01 Benchmark Circuit [7]. In [8], architecture of multiplier based on mathematics is discussed. Our design is based on 28nm FPGA (Kintex-7) and 40nm FPGA (Artix-7). For Kintex-7 device used is XC7K160T, package used is FBG676 and it is working on -3 speed grade. Same for Artix-7 the deviceused is XC7Q100T, package used is 2CSG324 and it is working on -2 speed grade.XPower Analyzer is used for power analysis.

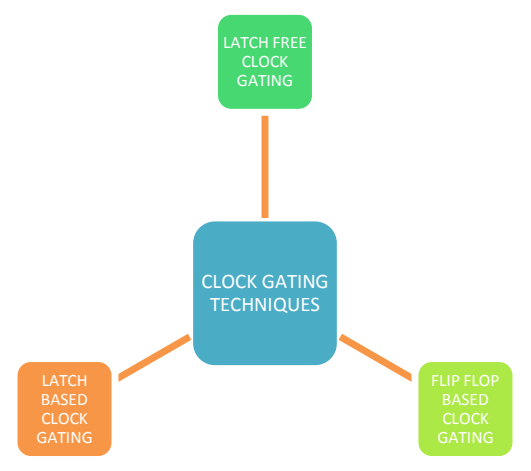

Figure 2. Clock Gating Techniques

We have taken different set of frequencies mentioned in Table 2, and have done power analysis by using Clock Gating Technique. The Clock Gating includes Gated and NonGated methods and by both methods we calculate Total power and Clock power. This can be shown in Figure 3. There are different techniques like capacitance scaling [8], thermal scaling [10], clock gating [11], various design goals [12], impedance matching, scalable scheme [9] and mapping. In this paper power analysis is our main concern and we have studied about the power analysis in this paper at different frequencies. Temperature is not kept constant it is varying and hence thermal analysis has also been done. For thermal 
analysis of our energy efficient design, we have taken temperatures of four different regions from reference [13]. Median temperature of Delhi is $40^{\circ} \mathrm{C}$ and standard normal temperature is $21^{\circ} \mathrm{C}$ [13]. In order to test the portability of our design [15-16], we are operating our design with respective frequency of different mobile architecture as illustrated in Table 2. e.g., Operating frequency of iPhone 6 is $2100 \mathrm{MHz}$.

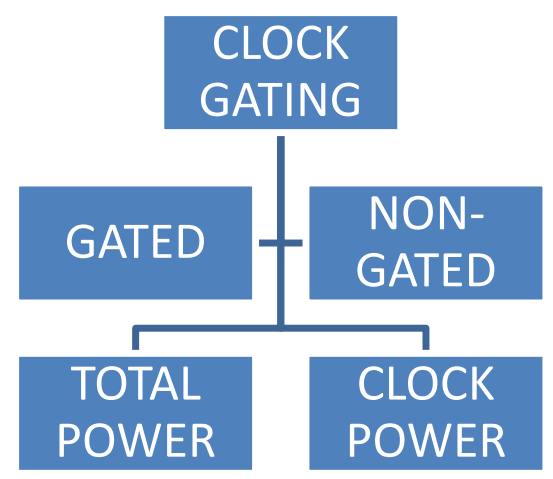

Figure 3. Clock Gating

\section{Power Analysis}

A. Power Analysis at 329.85 Kelvin Ambient Temperature

Table 3. Effect of Clock Gating and 28nm FPGA on Power Dissipation

\begin{tabular}{|c|c|c|c|c|}
\hline Frequency & $\begin{array}{c}\text { Non-gated } \\
\text { Total Power }\end{array}$ & $\begin{array}{c}\text { Non-gated } \\
\text { Clock Power }\end{array}$ & $\begin{array}{c}\text { Gated Total } \\
\text { Power }\end{array}$ & $\begin{array}{c}\text { Gated Clock } \\
\text { Power }\end{array}$ \\
\hline $1400 \mathrm{MHz}$ & 0.118 & 0.002 & 0.124 & 0.007 \\
\hline $1.2 \mathrm{GHz}$ & 0.117 & 0.002 & 0.121 & 0.006 \\
\hline $2100 \mathrm{MHz}$ & 0.123 & 0.004 & 0.131 & 0.010 \\
\hline $1700 \mathrm{MHz}$ & 0.120 & 0.003 & 0.127 & 0.008 \\
\hline $1800 \mathrm{MHz}$ & 0.120 & 0.003 & 0.128 & 0.009 \\
\hline $2.2 \mathrm{GHz}$ & 0.123 & 0.004 & 0.132 & 0.011 \\
\hline
\end{tabular}

There is $4.83 \%$ for $1400 \mathrm{MHz}, 3.30 \%$ for $1.2 \mathrm{GHz}, 6.10 \%$ for $2100 \mathrm{MHz}, 5.51 \%$ for $1700 \mathrm{MHz}, 6.25 \%$ for $1800 \mathrm{MHz}, 6.81 \%$ for $2.2 \mathrm{GHz}$ saving in total power dissipation when we use non-gated clock instead of gated one on 28nm FPGA and temperature is $329.85 \mathrm{~K}$ ambient temperature as illustrated in Table 3 and Figure 4.

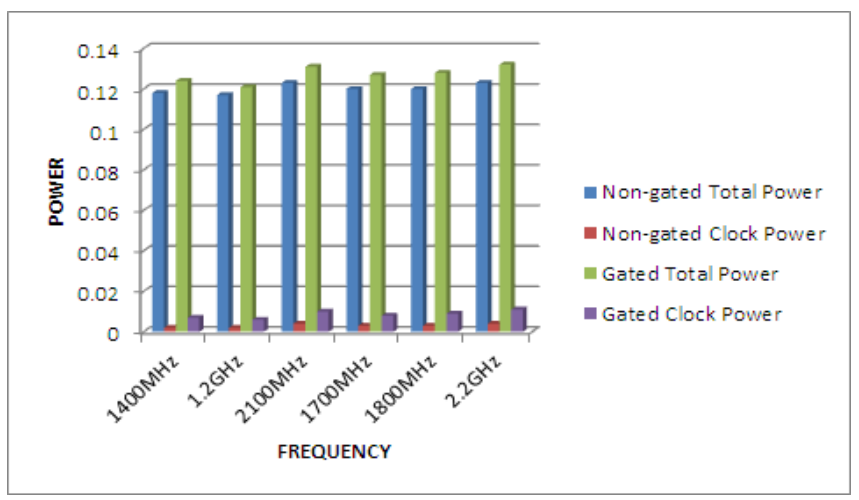

Figure 4. Power Analysis at 329.85Kon 28nm FPGA 
Table 4. Effect of Clock Gating and 40nm FPGA on Power Dissipation

\begin{tabular}{|c|c|c|c|c|}
\hline Frequency & $\begin{array}{c}\text { Non-gated } \\
\text { Total Power }\end{array}$ & $\begin{array}{c}\text { Non-gated } \\
\text { Clock Power }\end{array}$ & $\begin{array}{c}\text { Gated Total } \\
\text { Power }\end{array}$ & $\begin{array}{c}\text { Gated Clock } \\
\text { Power }\end{array}$ \\
\hline $1400 \mathrm{MHz}$ & 0.100 & 0.003 & 0.105 & 0.007 \\
\hline $1.2 \mathrm{GHz}$ & 0.098 & 0.002 & 0.103 & 0.006 \\
\hline $2100 \mathrm{MHz}$ & 0.105 & 0.004 & 0.113 & 0.010 \\
\hline $1700 \mathrm{MHz}$ & 0.102 & 0.003 & 0.108 & 0.008 \\
\hline $1800 \mathrm{MHz}$ & 0.102 & 0.003 & 0.110 & 0.009 \\
\hline $2.2 \mathrm{GHz}$ & 0.105 & 0.004 & 0.114 & 0.011 \\
\hline
\end{tabular}

There is $4.76 \%$ for $1400 \mathrm{MHz}, 4.85 \%$ for $1.2 \mathrm{GHz}, 7.07 \%$ for $2100 \mathrm{MHz}, 5.55 \%$ for $1700 \mathrm{MHz}, 7.27 \%$ for $1800 \mathrm{MHz}, 7.89 \%$ for $2.2 \mathrm{GHz}$ saving in total power dissipation when we usenon-gated clock instead of gated one on 40nm FPGA and temperature is $329.85 \mathrm{~K}$ ambient temperature as illustrated in Table 4 and Figure 5.

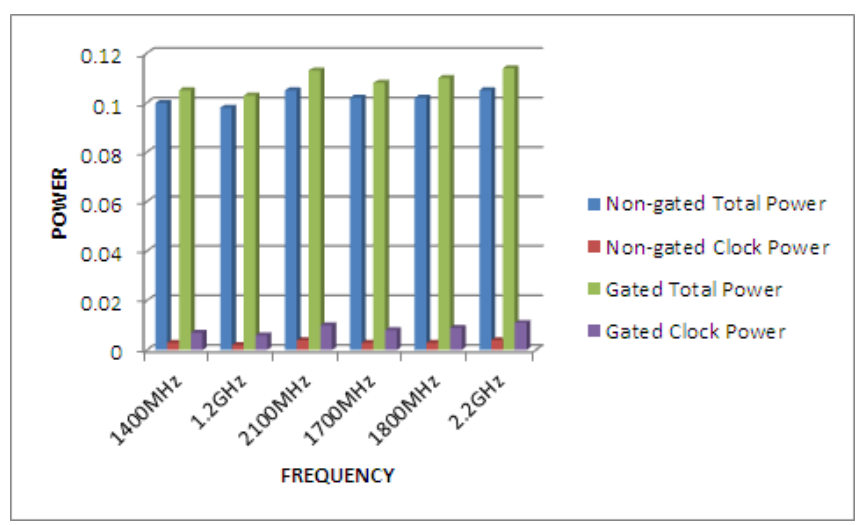

Figure 5. Total Power Analysis at $56.7^{\circ} \mathrm{Celsius}$ on 40nm FPGA

B. Power Analysis at 326.65K Ambient Temperature

Table 5. Effect of Clock Gating and 28nm FPGA on Power Dissipation

\begin{tabular}{|c|c|c|c|c|}
\hline Frequency & $\begin{array}{c}\text { Non-gated } \\
\text { Total Power }\end{array}$ & $\begin{array}{c}\text { Non-gated } \\
\text { Clock Power }\end{array}$ & $\begin{array}{c}\text { Gated Total } \\
\text { Power }\end{array}$ & $\begin{array}{c}\text { Gated Clock } \\
\text { Power }\end{array}$ \\
\hline $1400 \mathrm{MHz}$ & 0.107 & 0.002 & 0.113 & 0.007 \\
\hline $1.2 \mathrm{GHz}$ & 0.105 & 0.002 & 0.110 & 0.006 \\
\hline $2100 \mathrm{MHz}$ & 0.111 & 0.004 & 0.120 & 0.010 \\
\hline $1700 \mathrm{MHz}$ & 0.109 & 0.003 & 0.116 & 0.008 \\
\hline $1800 \mathrm{MHz}$ & 0.109 & 0.003 & 0.117 & 0.009 \\
\hline $2.2 \mathrm{GHz}$ & 0.112 & 0.004 & 0.121 & 0.011 \\
\hline
\end{tabular}

There is $5.30 \%$ for $1400 \mathrm{MHz}, 4.54 \%$ for $1.2 \mathrm{GHz}, 7.5 \%$ for $2100 \mathrm{MHz}, 6.03 \%$ for $1700 \mathrm{MHz}, 6.83 \%$ for $1800 \mathrm{MHz}, 7.43 \%$ for $2.2 \mathrm{GHz}$ saving in total power dissipation when we use non-gated clock instead of gated one on 28nm FPGA and temperature is $326.65 \mathrm{~K}$ ambient temperature as illustrated in Table 5 and Figure 6. 


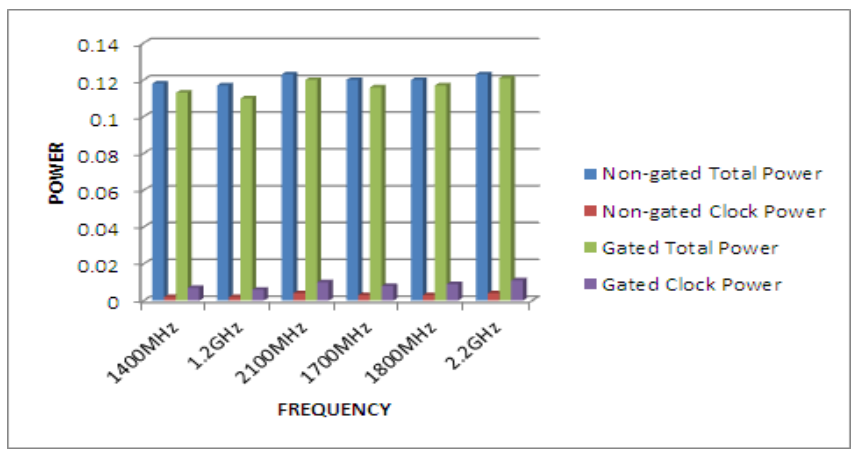

Figure 2. Power Analysis at 326.65Kon 28nm FPGA

Table 6. Effect of Clock Gating and 40nm FPGA on Power Dissipation

\begin{tabular}{|c|c|c|c|c|}
\hline Frequency & $\begin{array}{c}\text { Non-gated } \\
\text { Total Power }\end{array}$ & $\begin{array}{c}\text { Non-gated } \\
\text { Clock Power }\end{array}$ & $\begin{array}{c}\text { Gated Total } \\
\text { Power }\end{array}$ & $\begin{array}{c}\text { Gated Clock } \\
\text { Power }\end{array}$ \\
\hline $1400 \mathrm{MHz}$ & 0.091 & 0.003 & 0.097 & 0.007 \\
\hline $1.2 \mathrm{GHz}$ & 0.090 & 0.002 & 0.095 & 0.006 \\
\hline $2100 \mathrm{MHz}$ & 0.096 & 0.004 & 0.104 & 0.010 \\
\hline $1700 \mathrm{MHz}$ & 0.093 & 0.003 & 0.100 & 0.008 \\
\hline $1800 \mathrm{MHz}$ & 0.094 & 0.003 & 0.101 & 0.009 \\
\hline $2.2 \mathrm{GHz}$ & 0.097 & 0.004 & 0.106 & 0.011 \\
\hline
\end{tabular}

There is $6.18 \%$ for $1400 \mathrm{MHz}, 5.26 \%$ for $1.2 \mathrm{GHz}, 7.69 \%$ for $2100 \mathrm{MHz}, 7 \%$ for $1700 \mathrm{MHz}, 7 \%$ for $1800 \mathrm{MHz}, 8.49 \%$ for $2.2 \mathrm{GHz}$ saving in total power dissipation when we use non-gated clock instead of gated one on 40nm FPGA and temperature is $326.65 \mathrm{~K}$ ambient temperature as illustrated in Table 6 and Figure 7.

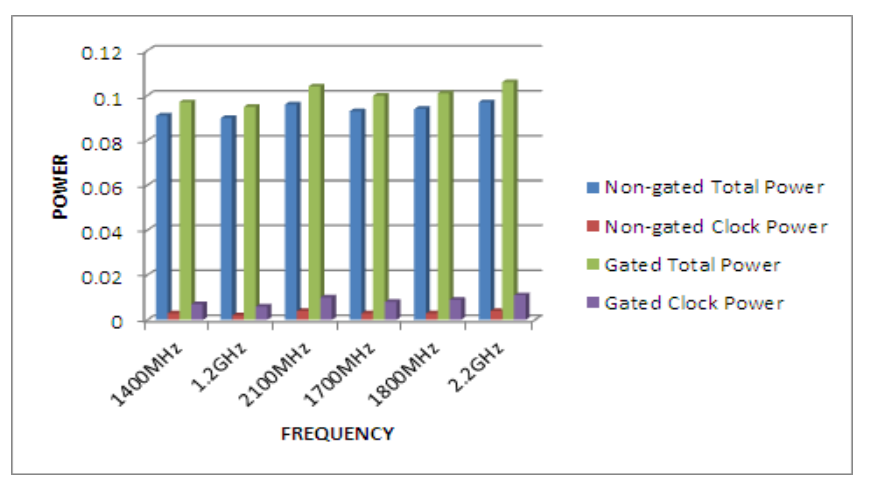

Figure 7. Power Analysis at 326.65K on 40nm FPGA

C. Power Analysis at 313.15K Ambient Temperature

Table 7. Effect of Clock Gating and 28nm FPGA on Power Dissipation

\begin{tabular}{|c|c|c|c|c|}
\hline Frequency & $\begin{array}{c}\text { Non-gated } \\
\text { Total Power }\end{array}$ & $\begin{array}{c}\text { Non-gated } \\
\text { Clock Power }\end{array}$ & $\begin{array}{c}\text { Gated Total } \\
\text { Power }\end{array}$ & $\begin{array}{c}\text { Gated Clock } \\
\text { Power }\end{array}$ \\
\hline $1400 \mathrm{MHz}$ & 0.073 & 0.002 & 0.079 & 0.007 \\
\hline $1.2 \mathrm{GHz}$ & 0.072 & 0.002 & 0.077 & 0.006 \\
\hline $2100 \mathrm{MHz}$ & 0.078 & 0.004 & 0.087 & 0.010 \\
\hline $1700 \mathrm{MHz}$ & 0.075 & 0.003 & 0.082 & 0.008 \\
\hline $1800 \mathrm{MHz}$ & 0.076 & 0.003 & 0.085 & 0.009 \\
\hline $2.2 \mathrm{GHz}$ & 0.079 & 0.004 & 0.088 & 0.011 \\
\hline
\end{tabular}


There is $7.59 \%$ for $1400 \mathrm{MHz}, 6.49 \%$ for $1.2 \mathrm{GHz}, 10.34 \%$ for $2100 \mathrm{MHz}, 8.53 \%$ for $1700 \mathrm{MHz}, 10.58 \%$ for $1800 \mathrm{MHz}, 10.22 \%$ for $2.2 \mathrm{GHz}$ saving in total power dissipation when we use non-gated clock instead of gated one on 28nm FPGA and temperature is $313.15 \mathrm{~K}$ ambient temperature as illustrated in Table 7 and Figure 8.

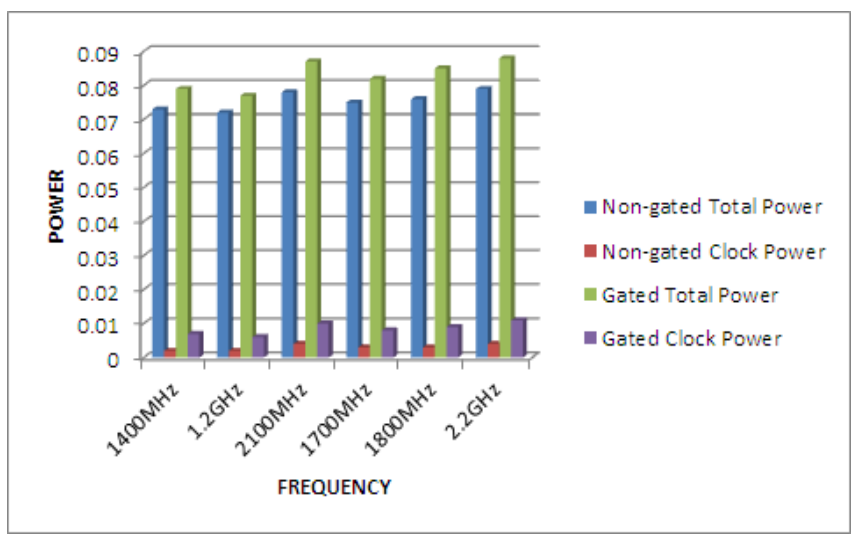

Figure 8. Power Analysis at 313.15K on 28nm FPGA

Table 8. Effect of Clock Gating and 40nm FPGA on Power Dissipation

\begin{tabular}{|c|c|c|c|c|}
\hline Frequency & $\begin{array}{c}\text { Non-gated } \\
\text { Total Power }\end{array}$ & $\begin{array}{c}\text { Non-gated } \\
\text { Clock Power }\end{array}$ & $\begin{array}{c}\text { Gated Total } \\
\text { Power }\end{array}$ & $\begin{array}{c}\text { Gated Clock } \\
\text { Power }\end{array}$ \\
\hline $1400 \mathrm{MHz}$ & 0.066 & 0.003 & 0.071 & 0.007 \\
\hline $1.2 \mathrm{GHz}$ & 0.065 & 0.002 & 0.069 & 0.006 \\
\hline $2100 \mathrm{MHz}$ & 0.071 & 0.004 & 0.079 & 0.010 \\
\hline $1700 \mathrm{MHz}$ & 0.068 & 0.003 & 0.075 & 0.008 \\
\hline $1800 \mathrm{MHz}$ & 0.069 & 0.003 & 0.076 & 0.009 \\
\hline $2.2 \mathrm{GHz}$ & 0.071 & 0.004 & 0.080 & 0.011 \\
\hline
\end{tabular}

There is $70.42 \%$ for $1400 \mathrm{MHz}, 5.79 \%$ for $1.2 \mathrm{GHz}, 10.12 \%$ for $2100 \mathrm{MHz}, 9.33 \%$ for $1700 \mathrm{MHz}, 9.21 \%$ for $1800 \mathrm{MHz}, 11.25 \%$ for $2.2 \mathrm{GHz}$ saving in total power dissipation when we use non-gated clock instead of gated one on 40nm FPGA and temperature is $313.15 \mathrm{~K}$ ambient temperature as illustrated in Table 8 and Figure 9.

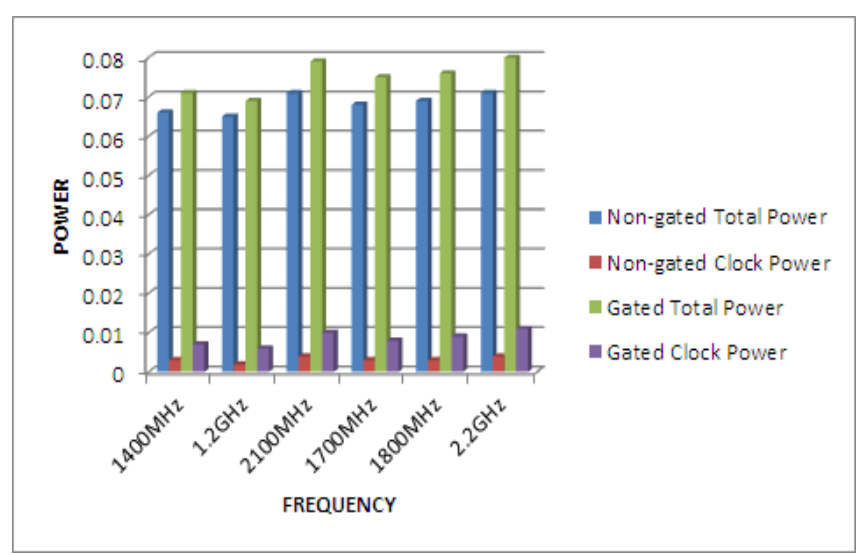

Figure 9.Power Analysis at 313.15K on 40nm FPGA 


\section{Power Analysis at 294.15KAmbient Temperature}

Table 9. Effect of Clock Gating and 28nm FPGA on Power Dissipation

\begin{tabular}{|c|c|c|c|c|}
\hline Frequency & $\begin{array}{c}\text { Non-gated } \\
\text { Total Power }\end{array}$ & $\begin{array}{c}\text { Non-gated } \\
\text { Clock Power }\end{array}$ & $\begin{array}{c}\text { Gated Total } \\
\text { Power }\end{array}$ & $\begin{array}{c}\text { Gated Clock } \\
\text { Power }\end{array}$ \\
\hline $1400 \mathrm{MHz}$ & 0.050 & 0.002 & 0.055 & 0.007 \\
\hline $1.2 \mathrm{GHz}$ & 0.048 & 0.002 & 0.053 & 0.006 \\
\hline $2100 \mathrm{MHz}$ & 0.054 & 0.004 & 0.063 & 0.010 \\
\hline $1700 \mathrm{MHz}$ & 0.051 & 0.003 & 0.058 & 0.008 \\
\hline $1800 \mathrm{MHz}$ & 0.052 & 0.003 & 0.060 & 0.009 \\
\hline $2.2 \mathrm{GHz}$ & 0.055 & 0.004 & 0.064 & 0.011 \\
\hline
\end{tabular}

There is $9.09 \%$ for $1400 \mathrm{MHz}, 9.43 \%$ for $1.2 \mathrm{GHz}, 14.28 \%$ for $2100 \mathrm{MHz}, 12.06 \%$ for $1700 \mathrm{MHz}, 13.33 \%$ for $1800 \mathrm{MHz}, 14.06 \%$ for $2.2 \mathrm{GHz}$ saving in total power dissipation when we use non-gated clock instead of gated one on 28nm FPGA and temperature is 294.15K ambient temperature as illustrated in Table 9 and Figure 10.

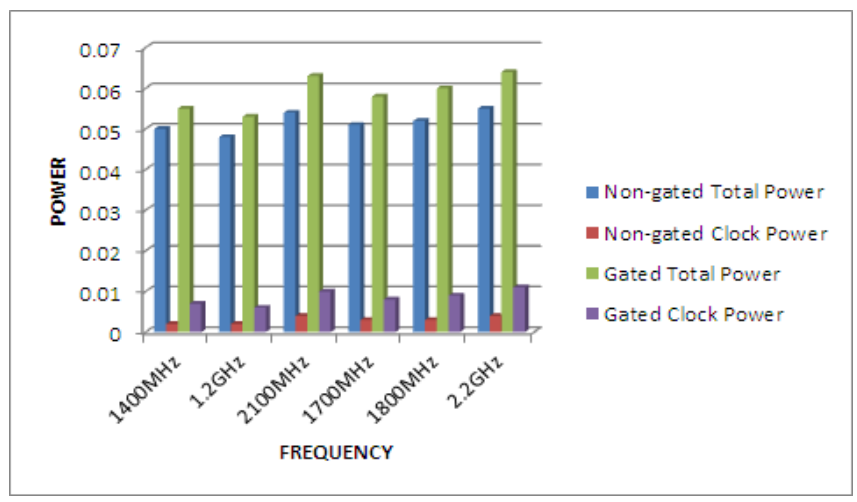

Figure 10. Power Analysis at $294.15 \mathrm{~K}$ on $28 \mathrm{~nm}$ FPGA

Table 10. Effect of Clock Gating and 40nm FPGA on Power Dissipation

\begin{tabular}{|c|c|c|c|c|}
\hline Frequency & $\begin{array}{c}\text { Non-gated } \\
\text { Total Power }\end{array}$ & $\begin{array}{c}\text { Non-gated } \\
\text { Clock Power }\end{array}$ & $\begin{array}{c}\text { Gated Total } \\
\text { Power }\end{array}$ & $\begin{array}{c}\text { Gated Clock } \\
\text { Power }\end{array}$ \\
\hline $1400 \mathrm{MHz}$ & 0.048 & 0.003 & 0.053 & 0.007 \\
\hline $1.2 \mathrm{GHz}$ & 0.047 & 0.002 & 0.051 & 0.006 \\
\hline $2100 \mathrm{MHz}$ & 0.053 & 0.004 & 0.061 & 0.010 \\
\hline $1700 \mathrm{MHz}$ & 0.050 & 0.003 & 0.057 & 0.008 \\
\hline $1800 \mathrm{MHz}$ & 0.051 & 0.003 & 0.058 & 0.009 \\
\hline $2.2 \mathrm{GHz}$ & 0.053 & 0.004 & 0.062 & 0.011 \\
\hline
\end{tabular}

There is $9.43 \%$ for $1400 \mathrm{MHz}, 7.84 \%$ for $1.2 \mathrm{GHz}, 13.11 \%$ for $2100 \mathrm{MHz}, 12.28 \%$ for $1700 \mathrm{MHz}, 12.06 \%$ for $1800 \mathrm{MHz}, 14.51 \%$ for $2.2 \mathrm{GHz}$ saving in total power dissipation when we use non-gated clock instead of gated one on 40nm FPGA and temperature is 294.15K ambient temperature as illustrated in Table 10 and Figure 11. 


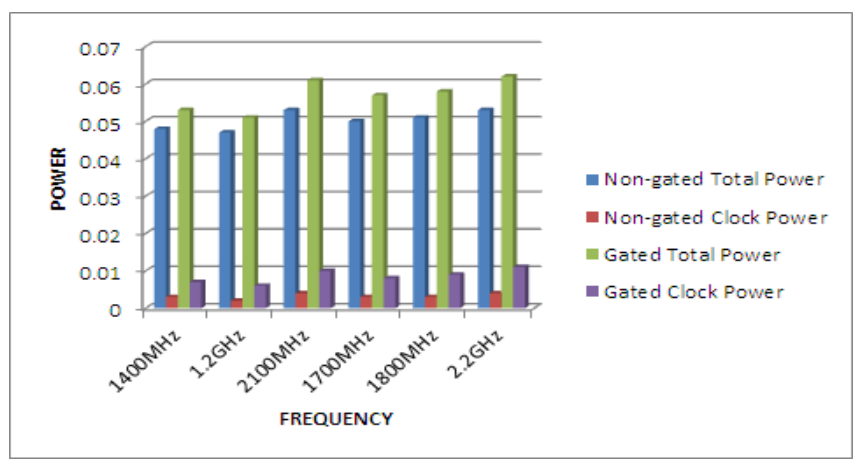

Figure 11. Power Analysis at 294.15K on 28 nm FPGA

E. Power Analysis ForDifferent Frequencies andDifferent Temperature on 28nm FPGA

Table 11. Variation in Power Dissipation with Frequency \& Thermal Scaling

\begin{tabular}{|c|c|c|c|c|}
\hline Frequency & $329.85 \mathrm{~K}$ & $326.65 \mathrm{~K}$ & $313.15 \mathrm{~K}$ & $294.15 \mathrm{~K}$ \\
\hline $1400 \mathrm{MHz}$ & 0.124 & 0.113 & 0.079 & 0.055 \\
\hline $1.2 \mathrm{GHz}$ & 0.121 & 0.110 & 0.077 & 0.053 \\
\hline $2100 \mathrm{MHz}$ & 0.131 & 0.120 & 0.087 & 0.063 \\
\hline $1700 \mathrm{MHz}$ & 0.127 & 0.116 & 0.082 & 0.058 \\
\hline $1800 \mathrm{MHz}$ & 0.128 & 0.117 & 0.085 & 0.060 \\
\hline $2.2 \mathrm{GHz}$ & 0.132 & 0.121 & 0.088 & 0.064 \\
\hline
\end{tabular}

From Table 11 and Figure 12, we can state that the maximum power consumption is at $2.2 \mathrm{GHz}$ and minimum power consumption is at $1.2 \mathrm{GHz}$. When we talk in terms of temperature, we can see that maximum power is consumed at $329.85 \mathrm{~K}$ and minimum power is consumed at $294.15 \mathrm{~K}$.

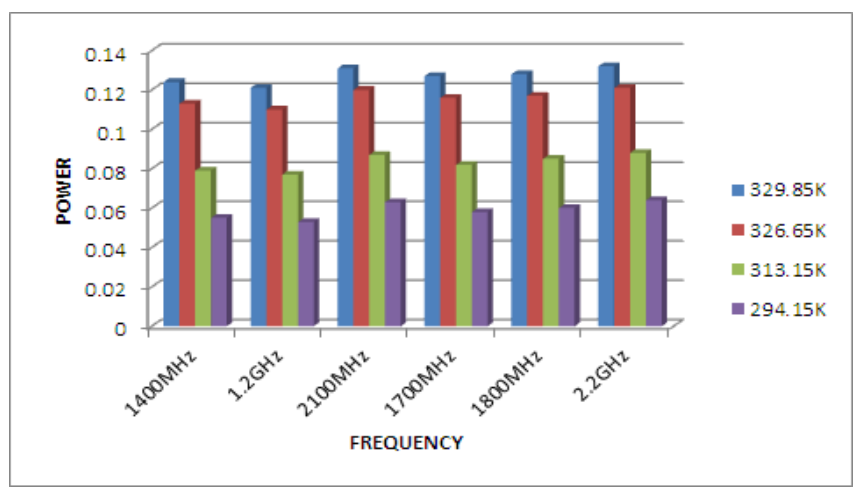

Figure 12. Power Dissipation with Frequency \& Temperature Variation

F. Power Analysis For Different Frequencies \& Different Temperature on 40nm FPGA

Table 12. Variation in Power Dissipation with Frequency \& Thermal Scaling

\begin{tabular}{|c|c|c|c|c|}
\hline Frequency & $329.85 \mathrm{~K}$ & $326.65 \mathrm{~K}$ & $313.15 \mathrm{~K}$ & $294.15 \mathrm{~K}$ \\
\hline $1400 \mathrm{MHz}$ & 0.105 & 0.097 & 0.071 & 0.053 \\
\hline $1.2 \mathrm{GHz}$ & 0.103 & 0.095 & 0.069 & 0.051 \\
\hline $2100 \mathrm{MHz}$ & 0.113 & 0.104 & 0.079 & 0.061 \\
\hline $1700 \mathrm{MHz}$ & 0.108 & 0.100 & 0.075 & 0.057 \\
\hline $1800 \mathrm{MHz}$ & 0.110 & 0.101 & 0.076 & 0.058 \\
\hline $2.2 \mathrm{GHz}$ & 0.114 & 0.106 & 0.080 & 0.062 \\
\hline
\end{tabular}


From Table 12 and Figure 13, we can state that the maximum power consumption is at $2.2 \mathrm{GHz}$ and minimum power consumption is at $1.2 \mathrm{GHz}$. When we talk in terms of temperature we can see that maximum power is consumed at $329.85 \mathrm{~K}$ and minimum power is consumed at $294.15 \mathrm{~K}$.

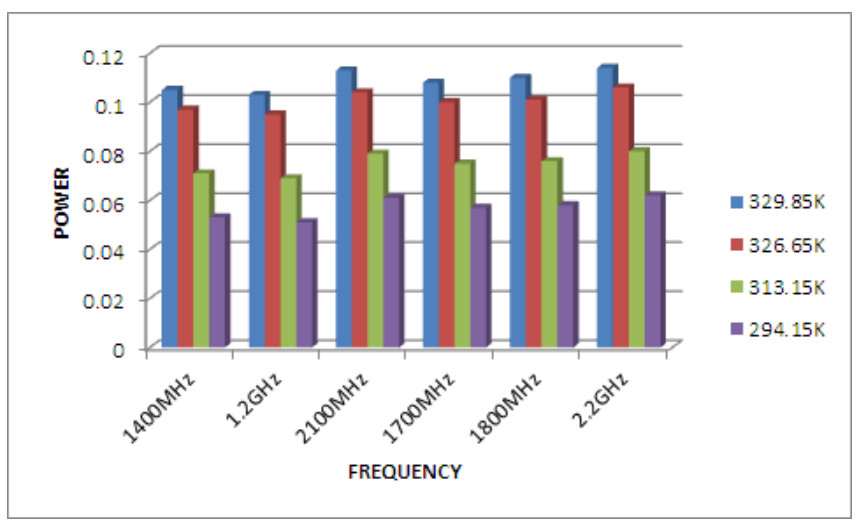

Figure 13. Power Dissipationwith Frequency\& Temperature Variation

G. Comparison between Kintex-7 and Artix-7 FPGA

Table 13. Total Power Analysis for 40nm and 28nm FPGA at 329.85K

\begin{tabular}{|c|c|c|}
\hline Frequency & Kintex-7 & Artix-7 \\
\hline $1400 \mathrm{MHz}$ & 0.124 & 0.105 \\
\hline $1.2 \mathrm{GHz}$ & 0.121 & 0.103 \\
\hline $2100 \mathrm{MHz}$ & 0.131 & 0.113 \\
\hline $1700 \mathrm{MHz}$ & 0.127 & 0.108 \\
\hline $1800 \mathrm{MHz}$ & 0.128 & 0.110 \\
\hline $2.2 \mathrm{GHz}$ & 0.132 & 0.114 \\
\hline
\end{tabular}

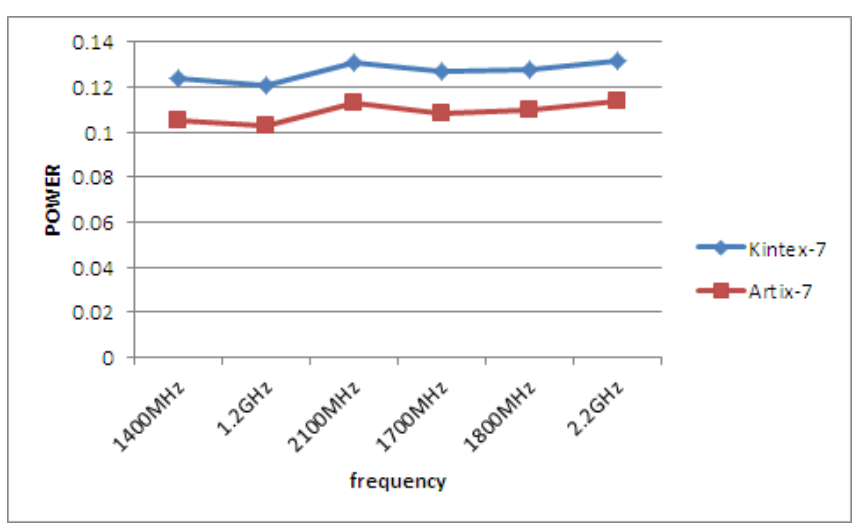

Figure 14. Total Power for Different Frequency and FPGA at 329.85K

Table 14. Total Power Analysis for 40nm and 28nm FPGA at 294.15K

\begin{tabular}{|c|c|c|}
\hline Frequency & Kintex-7 & Artix-7 \\
\hline $1400 \mathrm{MHz}$ & 0.055 & 0.053 \\
\hline $1.2 \mathrm{GHz}$ & 0.053 & 0.051 \\
\hline $2100 \mathrm{MHz}$ & 0.063 & 0.061 \\
\hline $1700 \mathrm{MHz}$ & 0.058 & 0.057 \\
\hline $1800 \mathrm{MHz}$ & 0.060 & 0.058 \\
\hline $2.2 \mathrm{GHz}$ & 0.064 & 0.062 \\
\hline
\end{tabular}




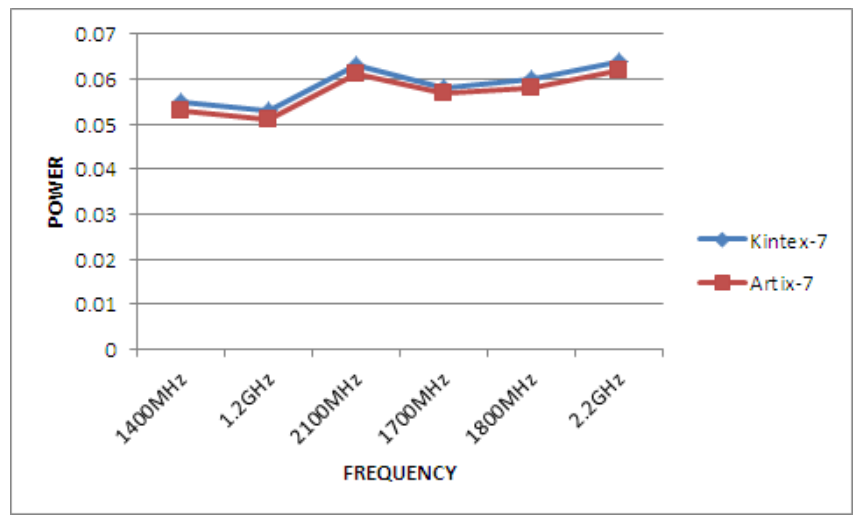

Figure 15. Total Power for Different Frequency and FPGA at 294.15K

From Table13-14 and Figure 14-15, we can state that the power dissipation is less in the case of 40nm (Artix-6) and is more in the case of 28nm (Kintex-7). Changing the parameter (Temperature) doesn't affect the clock power in both cases (Gated and Nongated).

\section{Conclusion}

Our design is based on 28nm FPGA (Kintex-7) and 40nm FPGA (Artix-7). In order to test the portability of our design, we are operating our design with respective frequency of different mobile architecture. In this paper we have done frequency scaling technique to obtain energy efficient design. For thermal analysis of our energy efficient design, we have taken temperatures of four different regions from reference. Latin Unicode reader takes 16-bit hexadecimal code of alphabet and clock input. And also the power dissipation is less in the case of 40nm (Artix-6) and is more in the case of 28nm (Kintex-7). Changing the parameter (Temperature) doesn't affect the clock power in both cases (Gated and Non-gated).

\section{References}

[1] S. Hussain and N. Durrani, "Urdu Domain Names", Multitopic Conference, 2006. INMIC'06. IEEE, IEEE, (2006).

[2] B. Pandey and M. Pattanaik, "Clock Gating Aware Low Power ALU Design and Implementation on FPGA”, Intl J. of Future Computer and Communication (IJFCC), ISSN: 2010-3751, vol. 2, no.5, (2013) October, pp. 461-465.

[3] M. P. Dev, "Clock Gated Low Power Sequential Circuit Design", IEEE Conf. on Information and Communication Technologies (ICT), (2013).

[4] B. Pandey, "Clock Gating Based Energy Efficient ALU Design and Implementation on FPGA", IEEE Int. Conf. on Energy Efficient Technologies for Sustainability-(ICEETs), (2013), pp. 93-97.

[5] T. Kumar, "64 Bit Green ALU Design Using Clock Gating Technique on Ultra Scale FPGA", IEEE Intl conf. on Green Computing", Communication and Conservation of Energy(ICGCE), (2013) December 12-14.

[6] B. Pandey, "Clock Gating Aware Low Power Global Reset ALU and Implemented On 28nm FPGA", IEEE Intl Conf on Computational Intelligence and Communication Networks (CICN), Mathura, (2013).

[7] V. P. Singh, "Power Reduction of ITC'99-b01 Benchmark Circuit Using Clock Gating Techniques", IEEE Intl Conf on Computational Intelligence and Communication Networks (CICN), Mathura, (2013).

[8] B. Pandey, "Capacitance scaling based energy efficient FIR filter for digital signal processing", Optimization, Reliabilty, and Information Technology (ICROIT), Intl Conf on (2014).

[9] P. C. Wu, L. G. Chen and T. D. Chiueh, "Scalable implementation scheme for multirate FIR filters and its application in efficient design of subband filter banks", IEEE transactions on circuits and systems for video technology, vol. 6, no. 4, (1996), pp. 407-410.

[10] K. Fushinobu and T. Hatakeyama, "Thermal scaling consideration of Si MOSFETs with gate length typically larger than $100 \mathrm{~nm}$ ", Semiconductor Thermal Measurement and Management Symposium (SEMI-THERM), 27th Annual IEEE, (2011). 
[11] Y. Zhang, "Automatic Register Transfer level CAD tool design for advanced clock gating and low power schemes", SoC Design Conference (ISOCC), (2012).

[12] Z. Liu and Z. Wang, "Analysis to Goal-Driven Design".

[13] T. Kumar, "IO Standard Based Thermal/Energy Efficient Green Communication For Wi-Fi Protected Access on FPGA", 6th International Congress on Ultra-Modern Telecommunications and Control systems and Workshops, St. Petersburg, Russia, (2014) October 06-08.

[14] S. S. Rahaman, "Design and development of a Bengali unicode font converter", Informatics, Electronics \& Vision (ICIEV), 2013 International Conference on. IEEE, (2013).

[15] S. H. A. Musavi, "IoTs Enable Active Contour Modeling Based Energy Efficient and Thermal Aware Object Tracking on FPGA", Springer Wireless Personal Communications, vol. 85, no. 2, (2015), pp. 529-543.

[16] T. Kumar, "Mobile DDR IO Standard Based High Performance Energy Efficient Portable ALU Design on FPGA", Springer Wireless Personal Communications, An International Journal, vol. 76, no. 3, (2014), pp. 569-578. 
International Journal of $u-$ and e- Service, Science and Technology Vol.9, No. 8 (2016) 